L. González, G. Masiero

Disentangling spillover effects of antibiotic consumption : a spatial panel approach

Quaderno N. 11-06

Decanato della Facoltà di Scienze economiche

Via G. Buffi, 13 CH-6900 Lugano 


\title{
Disentangling spillover effects of antibiotic consumption: a spatial panel approach
}

\author{
L. González * G. Masiero ${ }^{\dagger}$
}

August 2011

\begin{abstract}
Literature on socioeconomic determinants of antibiotic consumption in the community is limited to few countries using cross-sectional data. This paper analyses regional variations in outpatient antibiotics in Italy using a balanced panel dataset covering the period 2000-2008. We specify an econometric model where antibiotic consumption depends upon demographic and socioeconomic characteristics of the population, the supply of health care services in the community, and antibiotic copayments. The model is estimated by means of Ordinary least squares techniques with fixed effects (FE). The implications of consumption externalities across geographical areas are investigated by means of spatial-lag and spatial-error models (SLFE and SEFE). We find significant and positive income elasticity and negative effects of copayments. Antibiotic use is also affected by the age structure of the population and the supply of community health care. Finally, we find evidence of spatial dependency in the use of antibiotics across regions. This suggests that regional policies (e.g. public campaigns) aimed at increasing efficiency in antibiotic consumption and controlling bacterial resistance may be influenced by policy makers in neighbouring regions. There will be scope for a strategic and coordinated view of regional policies towards the use of antibiotics.
\end{abstract}

Keywords: Antibiotic consumption. Socioeconomic inequalities. Spatial dependency. Regional policies.

JEL classification: I0; C3

\footnotetext{
*Department of Economics, University of Lugano, 6900 Lugano, Switzerland

${ }^{\dagger}$ Department of Economics and Technology Management, University of Bergamo, 24044 Dalmine (BG), Italy; Department of Economics, University of Lugano, 6900 Lugano, Switzerland. Corresponding author. E-mail: giuliano.masiero@unibg.it. We are grateful to Massimo Filippini whose comments and suggestions generated significant improvements to the paper. Comments and suggestions from participants to the 11th National Health Economics Conference of the Portuguese Health Economics Association, Porto, 8-10 October 2009, and the 10th National Health Economics Conference of the Italian Health Economics Association, Bergamo, 29-30 October 2009, are gratefully acknowledged. The usual caveat applies.
} 


\section{Introduction}

The increasing use of antibiotics and the consequent harmful effects of bacterial resistance represent a growing problem in many countries. Evidence suggests that bacterial resistance grows with antibiotic use (Monroe and Polk, 2000; Mera et al., 2006). Although the effects of intervention policies on resistance to antimicrobial drugs cannot be assessed accurately at present, public interventions may be effective in controlling antibiotic consumption (Huttner et al., 2010). Consequently, the investigation of socioeconomic inequalities in the use of antibiotics across geographic areas is an important approach in understanding causes of consumption and building effective intervention policies.

Literature shows that outpatient antibiotic consumption, measured by the number of defined daily doses per 1000 inhabitants (DID), is highly heterogeneous across European countries (Elseviers et al., 2007). For instance, the consumption of antimicrobials in France is almost three times the consumption in the Netherlands. Generally, southern European countries exhibit higher levels of consumption as compared to northern European countries.

Outpatient antibiotic consumption is also highly heterogeneous across geographic areas within a country (Kern et al., 2006). To our knowledge, the study of socioeconomic determinants of consumption has been applied to few countries (Matuz et al., 2005; Filippini et al., 2006; Nitzan et al., 2010). Since previous studies are based on cross-sectional data, unobserved heterogeneity may stem from omitted common variables that affect geographic areas differently. These latent common factors may induce cross-section dependence and lead to inconsistent estimation coefficients in regressions if hidden aspects are correlated with the explanatory variables (see Cameron and Trivedi, 2005).

Spatial econometric approaches to antibiotic consumption are lacking. Geographic areas are usually treated as isolated entities, ignoring the fact that antibiotic consumption is plausibly affected by consumption in neighbouring regions. Spatial interactions in panel data are considered, for instance, by Revelli (2001) to investigate variations in tax rates across English districts, and by Costa-Font and Moscone (2008) to study health expenditure across Spanish regions. As for antibiotics, spatial aspects are partially addressed in recent studies by Filippini et al. (2009a, 2009b) using cross-sectional data. Spatial dependency plays an important role in the use of antibiotics for two main reasons. First, antibiotics are used to cure infections which may spread to other individuals in the community. Second, antimicrobial resistance partially generated by the intensive use of antibiotics may reduce antibiotic effectiveness for other individuals in the community. It follows that regional policies (e.g. public campaigns) aimed at increasing efficiency in antibiotic consumption and controlling bacterial resistance could blunt the impact of policies in neighbouring regions through the generation of local spillovers. This may suggest that the lack of coordination of regional policies towards the use of antibiotics leads to inefficiency.

The purpose of this study is to investigate socioeconomic factors affecting regional variations in outpatient antibiotic use in Italy over a relatively large period of 
time (2000-2008), by means of panel data analysis which takes the external effects of consumption into account. The use of panel data makes it possible to specify fixed regional effects in order to take the unobserved heterogeneity into account. A novelty of our work is that it focuses on a country, Italy, of which socioeconomic determinants of antibiotic use in outpatients have not been investigated so far. The relevance of this focus also originates from the peculiar organization of the Italian health care system, which is based upon a National Health Service where the provision of health care is substantially devolved to regional health authorities. A question arises as to whether the effects of main socioeconomic determinants of consumption are similar in countries with different health care organizations, since previous studies are conducted in health care systems based upon health insurance plans.

According to a recent report of the European Commission (2010), Italy is the most consuming country of antibiotics in Europe with relatively poor levels of public awareness of antibiotic efficacy. This suggests that the investigation of factors affecting the use of antibiotics may raise more concern compared to other countries. Similarly to previous studies, our model hypothesises that regional consumption of outpatient antibiotics in Italy depends on antibiotic price (copayments), the level of education, population age structure and income, the supply of health care services in the community, and the health status of the population. The model is estimated by means of Ordinary least squares with fixed effects (FE). Consumption externalities between regions are investigated by means of spatial-lag and spatial-error models with fixed effects (SLFE and SEFE). Spatial lags may reflect interactions between regions whereas spatial errors occur because regions have unobserved factors in common.

The remaining of the paper is organized as follows. Section 2 provides an overview of the literature on socioeconomic determinants of antimicrobial use across geographic areas. In Section 3 we summarise the main features of the Italian market for primary care and antibiotic use in outpatients. The specification of the econometric model and the estimation approaches are presented in Section 4 and Section 5, respectively. Section 6 discusses the results and Section 7 concludes.

\section{A review on socioeconomic determinants of antibiotic consumption}

The literature on socioeconomic determinants of outpatient antibiotic consumption is limited to few empirical studies, although there are more general studies on the determinants of pharmaceuticals use (e.g. Costa-Font et al., 2007). We present five studies which investigate the impact of socioeconomic factors within countries. ${ }^{1}$ The main features of these studies - geographical setting, type of data, methodological approach, determinants cosidered and results - are summarised in Table 1.

\footnotetext{
${ }^{1}$ Regarding cross-country studies, we refer the reader to the recent analysis by Masiero et al. (2010) using European data.
} 


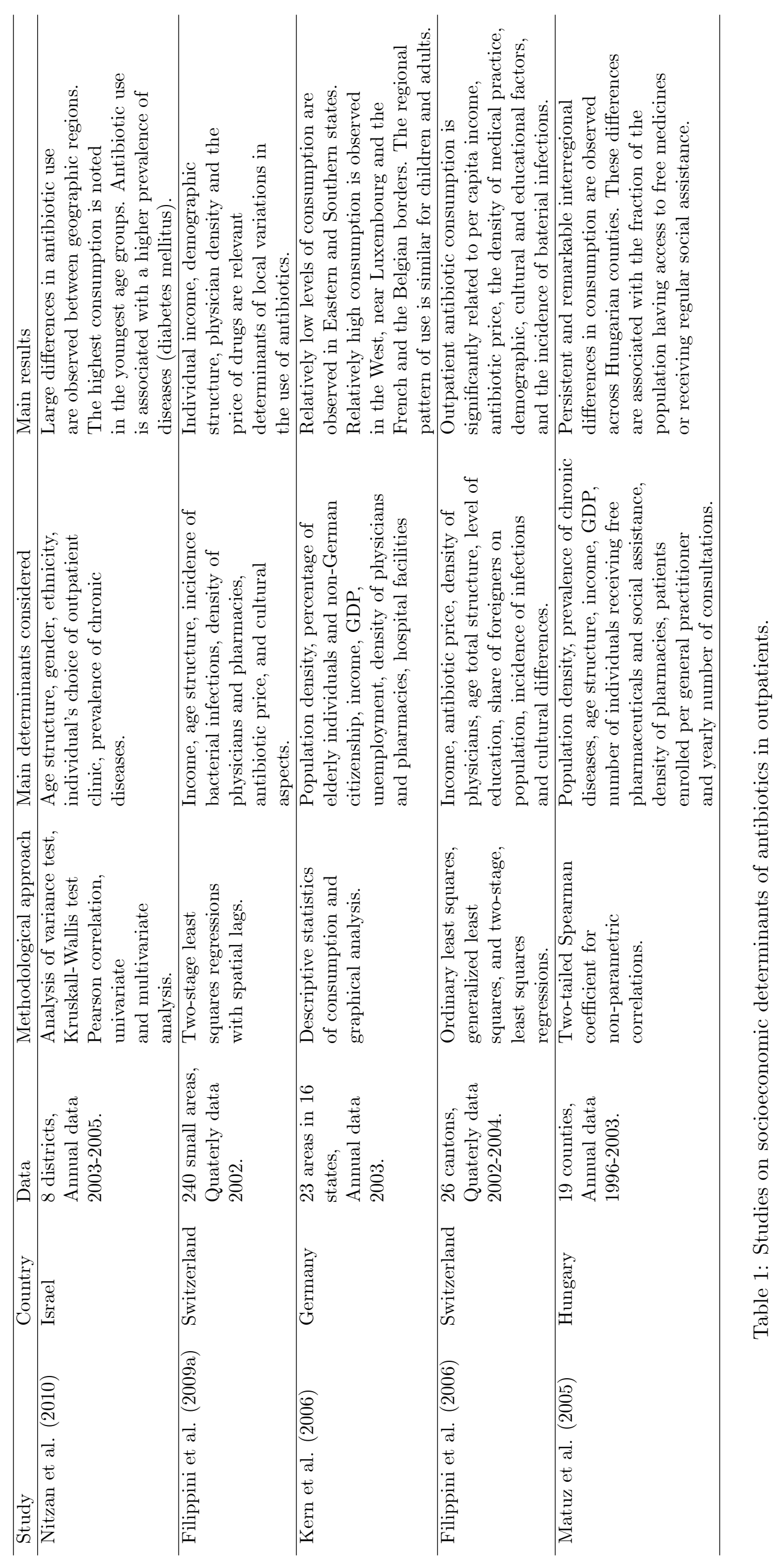


Nitzan et al. (2010) analyse the use of antibiotics in outpatients in 8 districts of Israel. The authors investigate consumption measured in defined daily doses per 1000 inhabitants for different age groups and for different groups of antibiotics. The study shows a decline in antibiotic use in all districts between 2003 and 2005 and large variation between districts. Results reveal that during the 3 years of the study the highest antibiotic consumption rates are observed for the youngest age groups (0-4, 5-18, and 19-44). Antibiotic consumption among individuals aged 65 or above is by far the lowest in all the age groups, probably due to higher hospitalization rates. Also, there is a significant association between a higher prevalence of diseases, such as diabetes mellitus, and higher antibiotic consumption. Conversely, higher rates of hospitalization seem to be correlated with lower levels of antibiotic consumption. Finally, the authors find large variability between the districts in the use of specific antibiotic groups. The use of penicillins in high consumption districts, for instance, is 2.8 times the use in low consumption districts. The magnitude of differences raises to 3.9 in the use of first-generation cephalosporines.

To investigate socioeconomic determinants of outpatient antibiotic use in Switzerland, Filippini et al. (2006) use regional consumption data and regress them against a set of variables suggested by the literature as plausible causal factors of the demand for drugs. The dataset includes quarterly data for 3 years (2002-2004) detailed at cantonal level (26 cantons). Findings show that Switzerland uses relatively low volumes of antibiotics in ambulatory care compared to other European countries, but large differences are observed across cantons. The authors specify an ad-hoc demand function for the cantonal per capita outpatient antibiotic use which depends upon the health status of individuals, income, antibiotic price, age, education, density of physicians and cultural aspects summarised by linguistic groups and borders with other countries. Since individuals health status and antibiotic price can be endogenous, the authors consider the inclusion of lagged values in the model and apply an instrumental variable approach. The per capita income, antibiotic price, the proportion of foreign residents, the density of medical practices, and cultural and educational differences are significant determinants of consumption. Among these results, it is worth noting that income has a positive impact on consumption, and antibiotic price has a negative and significant effect, as expected. Conversely, physician density is associated with higher levels of antibiotic use.

Kern et al. (2006) carry out an exploratory analysis on antibiotic prescriptions in Germany for the year 2003. They investigate variations in outpatient antibiotics between 23 areas in 16 states both for overall use and for the use of specific classes of antibiotics. Relatively low antibiotic consumption is observed in eastern and southern regions. Basic penicillins are the most frequently prescribed drugs with large regional variation. Regional patterns of use are similar for children and adults, although lower levels of consumption for children are observed in the south. The study does not find an association between overall antimicrobial consumption and population density, the percentage of elderly people, income, unemployment, gross domestic product and aspects of local health care supply, but the analysis lacks of a sound econometric approach. 
Filippini et al. (2009a) investigate inefficiencies in the use of outpatient antibiotics across small areas. The authors carry out econometric estimations using a two-stage least squares procedure on quarterly data of antibiotic use (in DID) in Swiss outpatients available for 240 small areas in 2002. A model is proposed in which antibiotic use varies according to the socioeconomic and demographic characteristics of the population, the incidence of infections, the local supply of health care and antibiotic price. The results suggest a positive relationship between antibiotic consumption and income, the proportion of children between 0 and 14 years of age, the percentage of foreigners in the total population, the incidence of infections, and density of pharmacies and physicians. On the other hand, antibiotic price and the proportion of individuals over 74 years of age show a negative and significant impact on antibiotic use. Some seasonal effects are found, which suggest that the per capita outpatient antibiotic use is lower in spring and summer periods. Finally, the authors consider the effects of spatial dependency in antibiotic consumption across the areas by means of spatial lags included in their model. The negative impact of antibiotic use in neighbouring areas suggests that the use of antibiotics in one area may reduce the spread of infections in neighbouring areas.

Finally, Matuz et al. (2005) investigate regional variations in antibiotic consumption in ambulatory care in Hungary. The sample is composed of 19 regions (counties) for the years 1996-2003. The authors find that antibiotic consumption was 21.1 DID in 1998, close to the European average, but decreases from 2002. The study shows large and stable interregional variations in consumption. The ranking of regions according to total antimicrobial consumption is basically the same during the whole period. The authors test associations between total antibiotic consumption and possible determinants of use by means of the two-tailed Spearman coefficient for non-parametric correlations. They do not find any significant relationship between antibiotic consumption and the average monthly net income nor with the demographic structure of the population. Conversely, a significant association with total antibiotic consumption is observed with the proportion of individuals receiving free access to selected medicines from the public health system without quantity limit and the proportion of individuals regularly receiving social assistance.

\section{Outpatient antibiotic consumption within the Italian NHS}

The Italian health care system is based upon a national health service (SSN) mainly financed by general taxation and characterised by universal access to health care for the entire population and asymmetric decentralization of health care provision to the 20 regions. Reforms over the 90's gave administrative and financial responsibility in the provision of health care to the regions. The central government retains limited supervisory control and continues to hold overall responsibility for the SSN to assure access and equal levels of health services across the country. The regions organise services that are designed to meet the needs of their local populations, define ways 


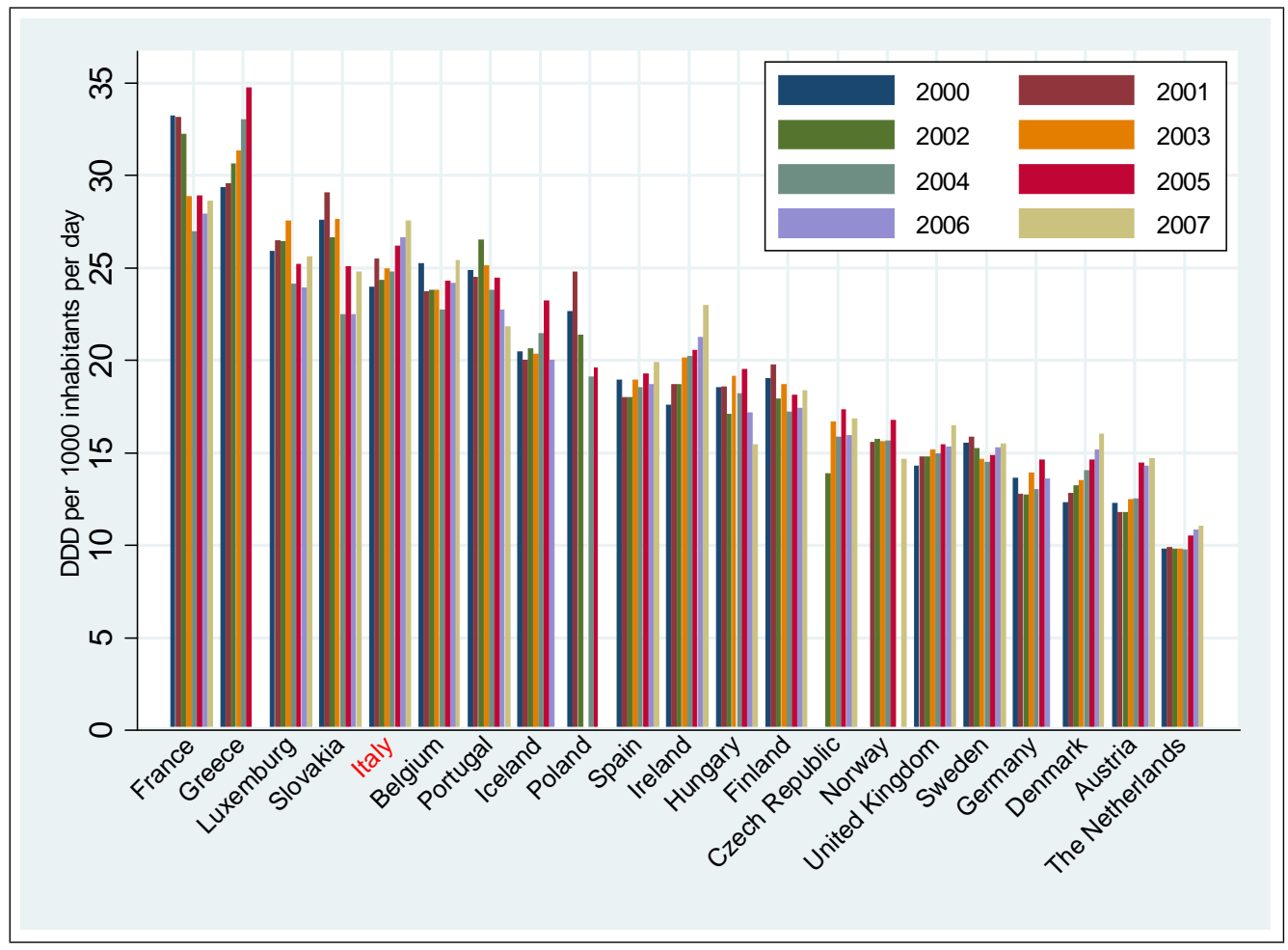

Figure 1: Outpatient antibiotic use in Europe by country (2000-2007). Data source: European Surveillance of Animicrobial Consumption (ESAC).

to allocate financial resources to the local health authorities (LHAs) within their territories, monitor health care services and activities provided by LHAs, and assess their performance.

Outpatient care in Italy is provided by general practitioners (GPs), paediatricians and specialists. General practitioners and paediatricians deliver primary care and preventive medicine and are mainly paid on a capitation basis. Generally, patients do not pay for visits to GPs. They also enjoy considerable freedom of choice of providers since they are only obliged to use providers in the province in which they reside and they must have a doctor's prescription for most forms of care. Patients can always change their GP within the province of residence (Atella et al., 2003). Specialists delivering outpatient care are paid on a fee-for-service basis. Patients pay only a small fraction of the full cost of a consultation if they are referred by their GP.

Medicines in outpatient care are classified in two categories. The first category (class A) includes essential medicines and medicines for serious and chronic diseases which require a doctor's prescription. These drugs are fully reimbursed by the SSN, although patients bear small copayments in some regions. Antibiotics are generally included in this category and the copayment (ticket) includes both a cost-sharing 


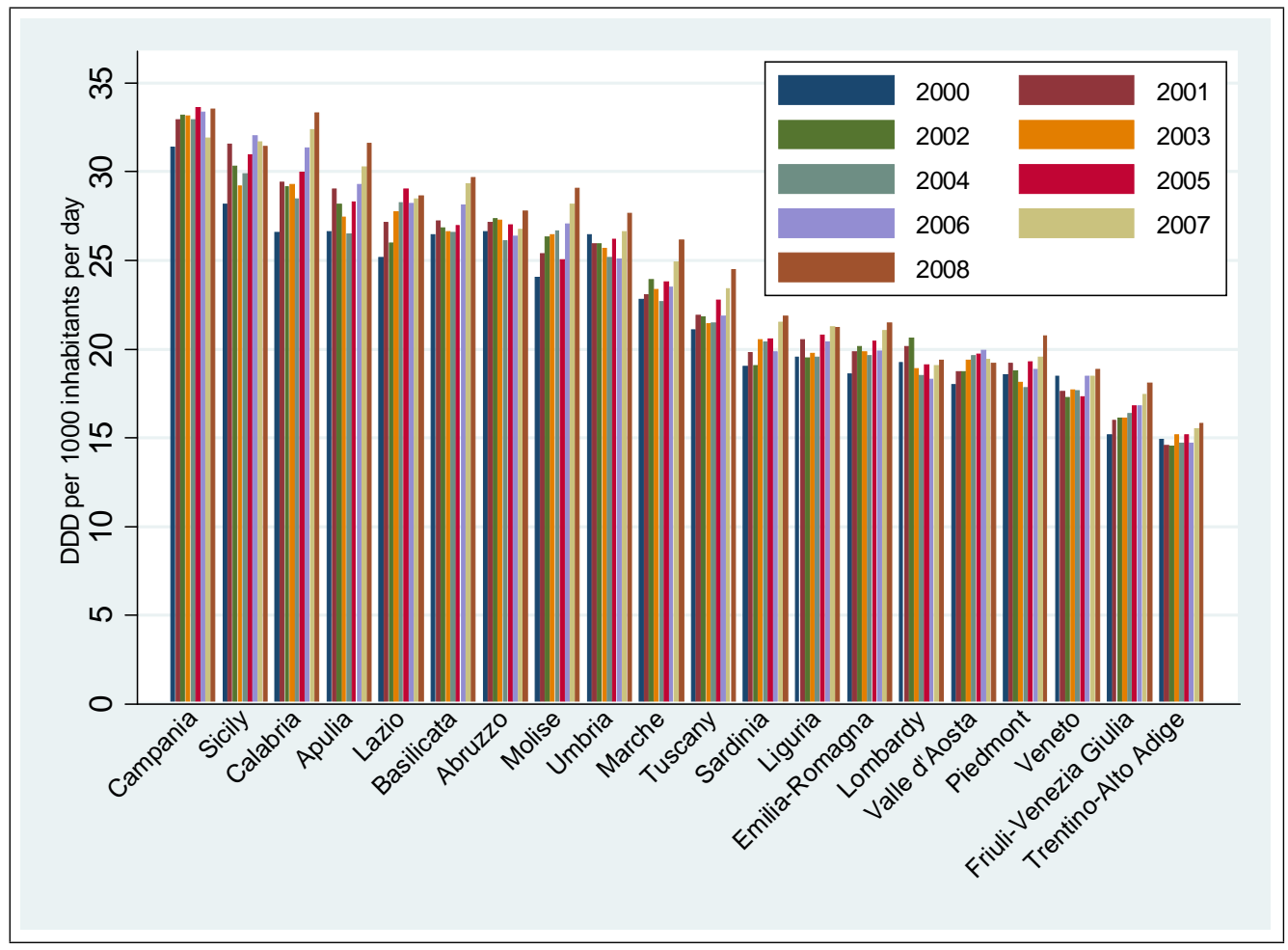

Figure 2: Outpatient antibiotic use in Italy by region (2000-2008). Data source: Italian National Observatory on Drugs Utilisation (OSMED).

scheme and a reference pricing one. ${ }^{2}$ According to this, patients are required to contribute to the cost of antibiotics either by a fixed amount per prescription or by a proportional-to-final price amount, or by paying the difference between the final price and the reference price. ${ }^{3}$ Generally, people with chronic or rare diseases, disabled people, pregnant women and low income people benefit from exemptions. The reference price is set for drugs which contain the same active ingredient, identical pharmaceutical dosage and package size. The second category of drugs - the so-called "class C" - includes medicines for minor diseases and ailments, medicines the use of which is discouraged and those not requiring a medical prescription. Pharmaceutical products included in this category are not reimbursed by the SSN.

As concerning the use of outpatient antibiotics, Italy is a relatively high-consuming country. Using available data from the European Surveillance of Antimicrobials Consumption (ESAC) between 2000 and 2007 we can rank Italy among European countries according to the number of defined daily doses per 1000 inhabitants consumed (Figure 1). Italy ranks among the most consuming countries, just below

\footnotetext{
${ }^{2}$ In Italy only $1 \%$ of antibiotic courses are obtained from a pharmacy without a prescription.
}

${ }^{3}$ See Fiorio and Siciliani (2010) for details. 


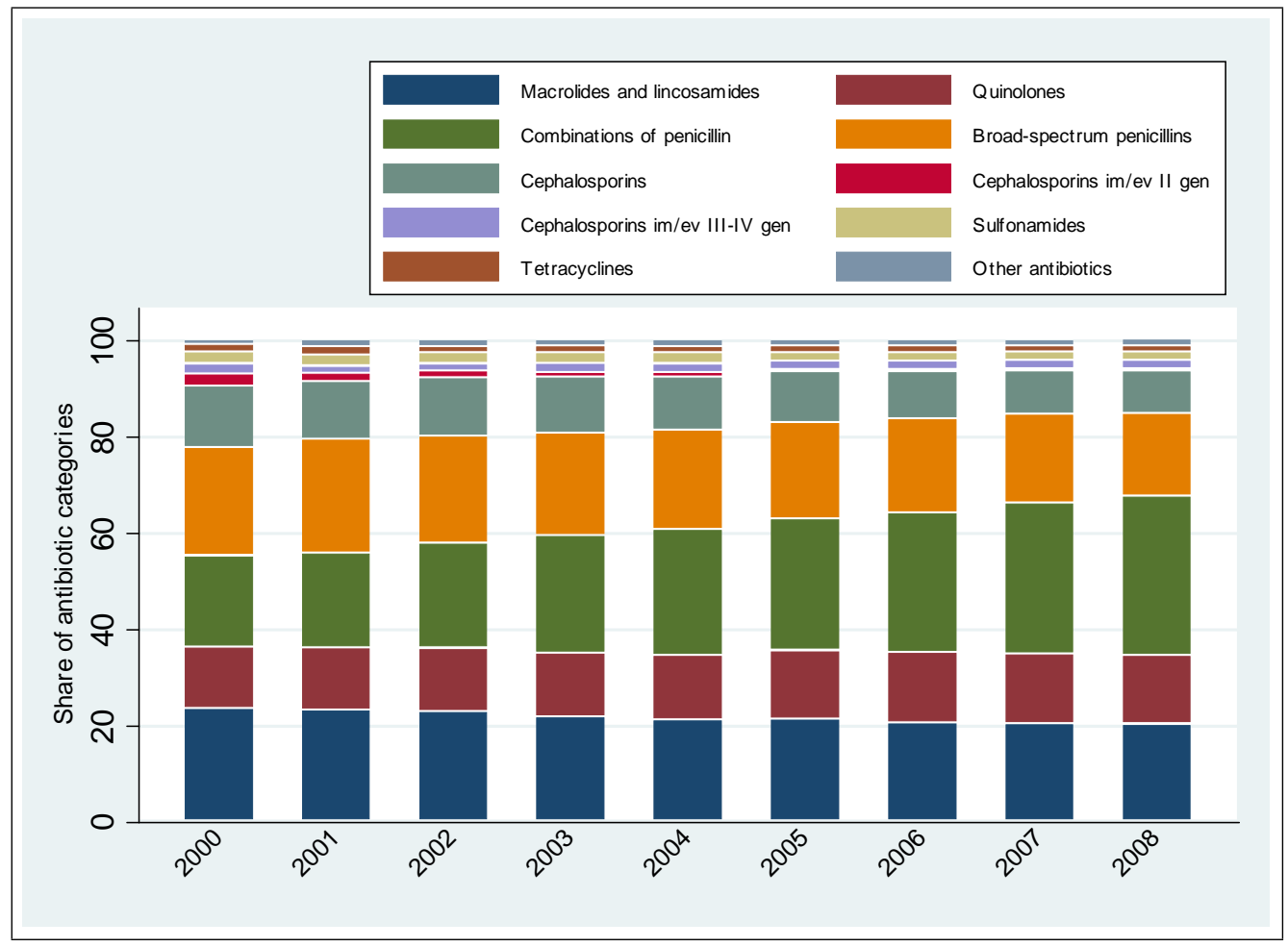

Figure 3: Outpatient antibiotic use in Italy by antibiotic categories (2000-2008). Data source: Italian National Observatory on Drugs Utilisation (OSMED).

France, Israel, Luxemburg and Slovakia. In contrast, the Netherlands, Austria and Denmark are among the least consuming countries. A recent survey by the European Commission (2010) indicates that Italy had the highest rate of antibiotic use across Europe between December 2008 and November 2009. Moreover, the majority of the population (51\%) think that antibiotics are effective against common infections, such as cold or flu, which are not cured by antibiotics. This evidence raises concern about the efficient use of antibiotics in the country.

The mean level of consumption of outpatient antibiotics in Italy between 2000 and 2008 was 23.53 DID, with a peak in 2008 (25.01 DID) and a minimum in 2000 (22.36 DID). ${ }^{4}$ Figure 2 shows that antimicrobial use has been roughly stable over this period but a remarkable degree of heterogeneity in consumption is observed across the regions. Generally, regions in central Italy use more antibiotics per capita (24.94 DID) than regions in the north (18.43 DID) and less than southern regions and the islands (28.74 DID).

The largest mean share of consumption during the time period considered is represented by the combinations of penicillin with beta-lactamase inhibitor (25.76\%),

${ }^{4}$ Data are collected by the Italian agency for drugs (AIFA). 
followed by the macrolides (21.57\%). Other categories of antimicrobials predominately used in the community are the broad-spectrum penicillins (20.59\%) and the quinolones (13.64\%). The structure of consumption has slightly changed over the 8year period (Figure 3). The share of combination of penicillin increased from $18.88 \%$ in 2000 to $31.10 \%$ in 2008 . This increase was partially compensated by a decrease in broad-spectrum penicillins, from $22.45 \%$ in 2000 to $17.20 \%$ in 2008 . In this respect, it is worth noting that changes in the use of antibiotic classes are associated to subsequent changes in bacterial resistance. It has been observed that current penicillin resistance depends on the cumulative consumption in the previous two years (Albricht et al., 2004). The substitution of broad-spectrum penicillins with combination of penicillin with beta-lactamase inhibitors is at least partially explained by the reduced effectiveness of the former category due to increasing bacterial resistance and the availability of a more dynamic subclass of penicillins (Ferech, et al., 2006).

\section{Model specification and data}

We propose a reduced-form consumption function for outpatient antibiotics, ${ }^{5}$ where the variability in antibiotic use among Italian regions depends on socioeconomic characteristics of the population (age structure and income), the supply of health care, individuals health status, and the price (copayment) of antibiotics. Antibiotic consumption in different periods is assumed to be fully separable (Bretteville-Jensen, 2006). This means that current consumption affects consumer's utility in the current period only, without consumer's preferences interactions across time periods.

The following model is specified:

$$
D I D_{i t}=f\left(Y_{i t}, P_{i t}, D P H_{i t}, P O P 1_{i t}, P O P 2_{i t}, I N F_{i t}\right),
$$

where the subscript $i$ denotes the region and $t$ the time period. $D I D_{i t}$ is antibiotic consumption per capita; $P O P 1_{i t}$ is the proportion of the population below 25 years and $P O P 2_{i t}$ indicates the proportion of the population older than $64 . \mathrm{DPH}_{i t}$ is the density of general practices and $I N F_{i t}$ is the mortality rate from infectious diseases, which is a proxy for individuals health status. Finally, the model includes income $\left(Y_{i t}\right)$ and copayment for pharmaceuticals $\left(P_{i t}\right) .^{6}$

For the estimation of equation (1) we use a "hybrid" log-log functional form. ${ }^{7}$ The log transformation is applied to income and copayment only since the other

\footnotetext{
${ }^{5}$ Within the Italian NHS, outpatient antibiotic consumption originates from prescriptions by general practitioners. We hypothesize that the demand for antibiotics for patients registered in the GP's list is defined by the representative general practitioner in the region by taking patients' needs and preferences into account.

${ }^{6}$ There is evidence that income is strongly associated with education and is preferred as a determinant of inequalities in the use of health care services (Habitch et al., 2009).

${ }^{7} \mathrm{~A}$ linear functional form has also been considered. In this case, the results are less satisfactory in terms of goodness of fit and the significance of the coefficients.
} 
covariates are defined as percentage ratios. Equation (1) can then be written as:

$$
\begin{aligned}
\ln D I D_{i t}= & \beta_{0}+\beta_{1} \ln Y_{i t}+\beta_{2} \ln P_{i t}+\beta_{3} D P H_{i t}+\beta_{4} P O P 1_{i t} \\
& +\beta_{5} P O P 2_{i t}+\beta_{6} I N F_{i t}+\mu_{i t} .
\end{aligned}
$$

Coefficients $\beta_{4}$ and $\beta_{5}$ capture the effect of the young and the old population, respectively, as compared to the reference population group aged between 25 and 65 . $\mu_{i t}$ is an error component with standard normality assumptions.

Our dataset is a balanced panel which includes data for 9 years, from 2000 to 2008, for 20 Italian regions. Summary statistics are reported in Table 2. Data on regional outpatient antibiotic consumption are collected from annual reports prepared by the Italian National Observatory on Drugs Utilization (Osmed). The per capita consumption is measured by the number of defined daily doses (DDD) per 1000 inhabitants per day (DID). A DDD represents the standard dose necessary for one day of drug treatment in adults and is defined by an independent scientific committee answering to the WHO Collaborating Center for Drug Statistics Methodology. The DID measure can be interpreted as the number of persons (out of 1000) who are taking antibiotics on a given day (Monnet et al., 2004). Dataset comprise sales of antimicrobial drugs - group J of the Anatomical Therapeutic Chemical (ATC) classification - included in class A by the Italian NHS (see Section 3 above). These drugs require a doctor's prescription and are supplied virtually free of charge, against small patient copayments.

Information on the demographic structure of the population, per capita income, density of general practices and mortality from infectious diseases are obtained from the Italian National Institute of Statistics (Istat). Copayments are obtained from annual reports on pharmaceutical consumption and expenditure prepared by Osmed. Regional copayments vary from 0 to 4 Euros. We rescale the variable from 1 to 5 in order to avoid negative values in the $\log$ transformation. ${ }^{8}$ Mortality data for infectious diseases in 2004 and 2005 are not available. Since data are substantially stable before and after this period, we linearly interpolate mortality data from 2003 and 2006 to assign values to the years 2004 and 2005. We are aware that this approximation could create some bias in the estimation. We then carefully discuss the estimation results related to this covariate in Section 6 .

\section{Econometric approach}

Two main aspects have to be addressed for a correct approach to the estimation of equation (2): the panel structure of the data and the presence of spatial correlation of antibiotic consumption across regions. As suggested by Baltagi (2005), the use of panel data has some advantages compared to the use of pure time series or crosssectional data. Panel data allow to control for individual heterogeneity and are more

\footnotetext{
${ }^{8}$ Adding a positive scalar $(k)$ to the values of a covariate $(X)$ ensures that the function $\log (X+k)$ is always defined. See Gujarati (1995) for details.
} 


\begin{tabular}{llcccc}
\hline Variable & Description & Mean & Std. error & Min. & Max. \\
\hline$D I D$ & Defined daily doses per 1,000 pop. & 23.53 & 5.16 & 14.52 & 33.62 \\
$Y$ & Income per capita (in Euro) & 23,070 & 5,848 & 12,922 & 34,149 \\
$P$ & Copayment (in Euro) & 0.84 & 0.95 & 0 & 4 \\
POP1 & Proportion of population aged 0-24 & 24.46 & 3.59 & 18.45 & 33.59 \\
POP2 & Proportion of pop. aged above 64 & 20.01 & 2.78 & 13.86 & 26.79 \\
$D P H$ & Density of physicians per 1,000 pop. & 0.82 & 0.06 & 0.63 & 0.94 \\
$I N F$ & Mortality rate for infectious diseases & 0.99 & 0.34 & 0.25 & 1.81 \\
& per 100,000 pop. & & & & \\
\hline
\end{tabular}

Table 2: Descriptive statistics of variables (years 2000-2008).

informative. Furthermore, they present more variability and less collinearity, and provide more degrees of freedom and more efficient estimates. Finally, they offer the advantage that units are observed through time and this allows for a simplification of economic aspects that, otherwise, would be more difficult to study. The temporal dimension pertains to periodic observations of variables characterising cross-sectional units over time. Consequently, two sources of variation are identified: the variation within units over time (within variation) and the variation across units (between variation). These two sources of variation are differently considered by the most widely used econometric approaches to panel data: the pooled ordinary least-squares (OLS) model, the fixed-effects (FE) model and the random-effects (RE) model. Conversely, the spatial aspect pertains to the analysis of the effects of the dependent variable between units (regions). This aspect will be taken into account by means of adequate spatial econometrics estimators included in the above models.

We estimate a FE model, which is a linear regression approach where the intercept term varies cross-sectionally (over the individual units and/or over time). Thus, the common formulation of the model assumes that differences across units can be captured by differences in slopes terms. To test the hypothesis of homogeneity in the constant terms across regions and time periods, we previously run an $F$-test. The large $F$-test statistics suggests that a panel data approach via the FE estimator would give more efficient estimates compared to the pooled OLS approach.

An alternative to the FE approach is the RE model, where the individual term is a stochastic factor, independently and identically distributed across units. The Lagrange multiplier test (Breusch and Pagan, 1979) also indicates that the OLS model can be rejected in favour of the RE model. Moreover, using the Hausman test we verify the hypothesis that the individual-specific error terms are uncorrelated with the explanatory variables, i.e. the RE estimator may be inconsistent. Since the Hausman-test statistics is significant at less than $5 \%$ level, we decide to focus on the consistent fixed-effects estimator (see Cameron and Trivedi, 2005, for more details). Note also the relevance of the within variation in most of our covariates.

Concerning the spatial aspect, it is worth noting that regional antibiotic consumption can be affected by individuals' and physicians' attitudes towards antibiotics in adjacent regions. This externality problem can be taken into account by means of 
adequate spatial econometrics estimators. There are two notable ways to introduce spatial autocorrelation in regression models. These are the spatial-lag model and the spatial-error model. The former refers to a situation where antibiotic consumption in one region is affected by antibiotic consumption in nearby regions. The spatial-lag model is appropriate when there are spill-over effects from neighbouring regions. The latter model of spatial dependence focuses on the error term and assumes that error terms in different regions are correlated. This kind of spatial dependence occurs if there are variables that are omitted from the regression model but do have an effect on the dependent variable and are spatially correlated. It is the case, for instance, of random shocks spreading to neighbouring regions.

Both approaches requires the preliminary specification of a matrix of spatial weights $(W)$. This matrix contains information on the spatial association between observational units. We construct a contiguity matrix indicating which regions share a borderland. ${ }^{9}$ According to this proximity criterion, the elements of the spatial weight matrix are 1 if location $i$ is adjacent to location $j$, and zero otherwise. The matrix of spatial weights can then be used to test the presence of spatial autocorrelation.

We run two tests of spatial autocorrelation: the Moran's I (Moran, 1948; Cliff and Ord, 1973; 1981) and Geary's C statistics (Geary, 1954). Moran's I statistic is a weighted correlation coefficient formulated as a normalized quadratic form of the variables tested for spatial correlation. Variables are standardised by subtracting the sample mean and then deflated by the variance of the data (Anselin and Bera, 1998). Values range from -1 to +1 , where +1 indicates perfect positive correlation, 0 implies no spatial correlation (provided the number of observations is large), and -1 indicates perfect negative correlation. Moran's $I$ values can then be transformed to Z-scores for statistical hypothesis testing. The Geary's $C$ statistics gives a value between 0 and 2 . The lower value indicates a strong positive spatial autocorrelation. A value of 1 suggests that no spatial autocorrelation is present, whereas negative spatial association is suggested by a value greater than 1 (Goodchild, 1987). This test is inversely related to Moran's $I$ but is more sensitive to local rather than global spatial autocorrelation.

The spatial-lag model can be defined as:

$$
D I D=\rho W D I D+X \beta+\varepsilon,
$$

where $D I D$ is an $N x 1$ vector of observations on antibiotic consumption per capita, with $N=160 ; W D I D$ is the spatial lag of antibiotic consumption and $\rho$ is the spatial autoregressive parameter; $X$ is the $N x k$ matrix of explanatory variables, with $k=6$; $\beta$ is the vector of regression parameters and $\varepsilon$ is a vector of errors.

It is worth noting that spatial dependency is similar to having a lagged-dependent variable as an explanatory variable. The spatial-lag model represents a suitable approach to the study of spatial autocorrelation in antimicrobial consumption since it

\footnotetext{
${ }^{9}$ In the case of Sardinia and Sicily the weights were assigned on the basis of the network of maritime routes which links the two islands to the peninsula.
} 
assumes that antibiotic use is characterised by consumption externalities as suggested by the literature (Fingleton, 2003; Cabrer-Borrás and Serrano-Domingo, 2007). Indeed, antibiotics have a preventive effect since their use may provide external benefits to other individuals, and consequently, reduce the need for consumption in neighbouring areas. However, antibiotics may also produce negative externalities since their utilization may reduce antibiotic effectiveness (increasing bacterial resistance) which may spread to other areas.

As an alternative to the spatial-lag model, we apply the spatial-error model. This is more relevant than the spatial-lag approach when the distribution of residuals in different regions displays spatial correlation. Residual may be spatially correlated if aggregated shocks hit regional health authorities or there are unobservable risk factors concentrated across the areas (Moscone and Knapp, 2005). This effect may be due, for instance, to exogenous bacterial resistance breakdown spreading across the country.

The spatial-error model can be defined as:

$$
\begin{aligned}
D I D & =X \beta+\varepsilon \\
\varepsilon & =\lambda W \varepsilon+\mu,
\end{aligned}
$$

where $\lambda$ is the spatial-autoregressive coefficient and $\mu$ is a vector of errors that are assumed to be independently and identically distributed. Note from equation (5) that errors depend on the weighted average of errors in neighbouring regions.

Both spatial approaches have to deal with estimation bias. The multidirectional nature of spatial dependence in the spatial-error model implies that generalized leastsquares estimators are inconsistent. The spatial-lag model exhibits endogeneity that can be taken into account by instrumental variables or the general methods of moments techniques, but should preferably be solved using an appropriate maximum likelihood estimator (see Anselin 1988, for details).

In the context of panel data, fixed effects can be included in the estimation of equation (3), which leads to a fixed-effects spatial-lag model (SLFE). A maximum likelihood (ML) procedure can be used to estimate the model. ${ }^{10}$ Similarly, one can estimate a fixed-effects spatial error-model (SEFE) (see e.g. Elhorst, 2003) using equation (4) and (5). In both models, we use the lagged mortality rate instead of the mortality rate to tackle possible endogeneity related to the health status of the population. Our estimations are carried out using the statistical software STATA (version 11).

\section{$6 \quad$ Results}

Preliminary OLS regressions shows an $R^{2}$ adjusted of 0.77 (0.80 with a time trend or temporal dummy variables). The $F$ test is 91.91 (92.53 and 49.28 with a time

\footnotetext{
${ }^{10}$ The procedure developed by Pisati (2001) to investigate spatially correlated cross-sectional data using maximum likelihood can be easily adapted to estimate a fixed-effects spatial-lag model.
} 


\begin{tabular}{lcc}
\hline Test & Statistics & p-value \\
\hline Moran's I & 0.797 & 0.000 \\
Geary's C & 0.167 & 0.000 \\
\hline LM (lag) & 22.790 & 0.000 \\
Robust LM (lag) & 57.049 & 0.000 \\
LM (error) & 1.215 & 0.270 \\
Robust LM (error) & 35.473 & 0.000 \\
\hline
\end{tabular}

Table 3: Results of tests for spatial dependency.

trend and time dummies, respecitvely). This suggests that overall regressors have a significant impact on the dependent variable. Moreover, the mean Variance Inflation Factor is lower than 5. Finally, the Shapiro-Wilk test as well as the Jarque-Bera test for normality of errors cannot be rejected using the conventional $95 \%$ level of significance.

Our intial tests also indicate that the OLS model can be rejected in favour of the FE and the RE models. The Breusch and Pagan lagrangian multiplier test indicates that there are effects other than those captured by the exogenous variables in OLS regressions. The $F$ test that constant terms are homogeneous across regions and time periods is also rejected. Moreover, the Hausman test suggests that the FE approach should be preferred to the RE approach. The Hausman test has a value of 74.44 and a $p$-value of 0.00 . Consequently, the estimation results reported in Table 4 focus on the FE model.

To account for possible cross-sectional dependence, we also estimated a FE model using the Driscoll-Kraay correction to standard errors (Driscoll and Kraay, 1998). Ignoring cross-sectional correlation in the estimation of panel models can lead to severely biased statistical results. The statistical significance of the coefficients in our regression slighly improves when the Driscoll-Kraay correction is applied. Finally, to check the robustness of our results and address possible endogeneity of population health status we run separate regressions using the lag of mortality for infections and an instrumental variable approach using population density as instrument for infections. The main results are unchanged.

Generally, only a few coefficients are significant. Nevertheless, the goodness of fit of our preliminary estimation with OLS is not far from the results of previous analysis of antimicrobial use at regional level. Because we use a log-log functional form, we can interpret coefficients for income and price as elasticities. In the FE estimation, income elasticity is positive and highly significant. The result suggests that regions with higher levels of income, i.e. northern Italian regions, use more antibiotics compared to lower income regions, ceteris paribus. Generally, a 1\% increase in income increases antibiotic consumption by $0.64 \%$. Positive income effects for antimicrobials are also observed by Baye et al. (1997) using US data, and by Filippini et al. (2009a) using Swiss data. According to the authors, one possible explanation for this low elasticity value is that the increasing concern over the effects of bacterial resistance from the 


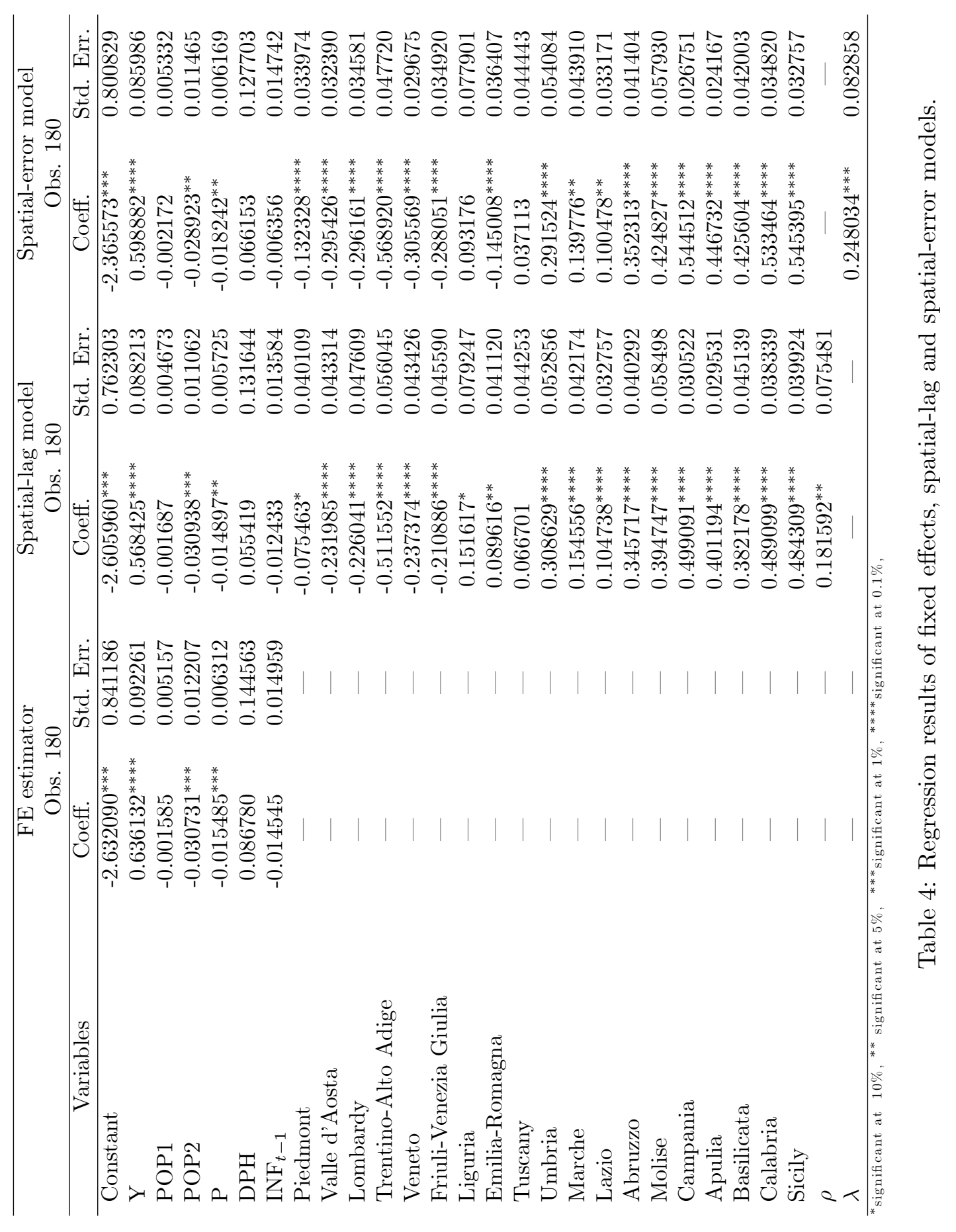


1990s may have reduced income elasticity of outpatient antibiotic expenditure over time. Another explanation is that individuals with higher income are more likely to substitute away antibiotics for alternative treatments when income increases.

As expected, copayment has a negative and significant impact on consumption $(-0.015)$. Many studies suggest that copayments are effective in reducing drug consumption at individual level (Freemantle and Bloor, 1996). Using data from Italy, Fiorio and Siciliani (2009) investigate the effect of copayments on the demand for pharmaceuticals. They find that an increase in copayments by $€ 1$ reduces the per capita number of prescriptions by $4 \%$ and the per capita public pharmaceutical expenditures by $3.4 \%$. Therefore, the effect of a variation in the level of copayment is not negligible. Our estimates are lower than those found by Contoyannis et al. (2005), who investigate exogenous changes in the cost-sharing of prescription drugs in Canada (between -0.12 and -0.16). Own-price elasticities calculated by Rudholm (2003) for three Swedish pharmaceutical submarkets between 1989 and 1996 are also lower (between -0.12 and -3.43 ).

Finally, we observe that the coefficient of mortality rate for infectious diseases $(-0.01)$ is not significant. This suggests that improvements in population health status are not significantly associated to increasing rates of antibiotic use.

The results of the two spatial models with fixed effects (SLFE and SEFE) are also reported in Table 4. For comparison purposes we run spatial random-effects estimations with maximum likelihood and observed that the sign and the significance of all the coefficients do not differ substantially from estimations with fixed effects. Table 3 summarises the results of two tests for spatial dependence: the Moran's $I$ test and the Geary's $C$ test. In both cases, the null hypothesis is rejected, which suggests evidence of spatial autocorrelation in antibiotic use among Italian regions. It is then advisable to extend our FE model to include interdependence of antibiotic consumption across regions by means of spatial models. In order to identify the appropriate form of spatial autocorrelation, we use two Lagrange multiplier (LM) tests and their robust versions. The LM test for a spatial lag and the LM test for spatially autoregressive errors both suggest the presence of spatial dependency (Table 3 ). The LM test statistics for the spatially lagged dependent variable are always significant at the $0.1 \%$ level. Regarding the model with spatially autoregressive errors, only the robust LM test statistic is significant at the $0.1 \%$ level. This leads us to conclude that there is no clear evidence in favour of one specification approach over the other. Estimation results for both spatial specification approaches are then discussed and reported in Table 4.

We estimate the spatial-lag model and the spatial-error model taking unobservable effects into account by means of regional dummies. The maximul likelihood procedure for spatial analysis of cross-sectional data developed by Pisati (2001) has been adapted to take fixed effects into account. Estimations with a time trend and time dummies have also been considered. Our results are robust to the inclusion of a time trend. The inclusion of temporal dummies reduces the significance of the spatial effects but the result is undermined by the large number of dummy variables (regional effects and temporal effects) and the small number of observations. 
The estimates of the two spatial models are quite similar. Region dummies are all highly significant with a couple of exceptions. Income is highly significant in both models. Antibiotic copayment is significant at less than 5\%. The proportion of people aged above 64 is also significant at less than $1 \%$ in the spatial-lag model and less than $5 \%$ in the spatial-error model. This suggests that elderly individuals are less likely to use outpatients antibiotics compared to younger individuals. According to the literature there is a $U$-shaped relationship between health care spending and age (Di Matteo, 2005). Young and elderly individuals generally use more health services than the mid-age population. In the case of outpatient antibiotics the relationship seems to be reinversed maybe because individuals in the labor force have higher opportunity cost of time and tend to shorten time to recover by means of drug therapy.

As for the spatial coefficients, these are significant in the spatial-lag and the spatial-error models at 5\% and $1 \%$ level respectively. One could argue that one of these two models captures the dynamics of the externalities involved (bacterial resistance and prevention from infections) better than the other. This would imply that the spillover process is either deterministic or similar to a random shock. One result of our analysis is that the spatial-lag parameter in the spatial-lag model $(\rho)$ is less significant than the spatial autocorrelation coefficient in the spatial-error model $(\lambda)$. This may suggest that random shocks related to the dynamics of infections may better explain spatial interactions between neighbouring areas in the consumption of antibiotics.

\section{Conclusions}

Most of the empirical evidence on socioeconomic determinants of antibiotic consumption is based on cross-sectional data and limited to few countries (e.g. Switzerland, Germany, Israel and Hungary). In particular, evidence lacks from countries with a National Health Service and substantial decentralization of health care provision to regional health authorities. The cross-sectional approach has some drawbacks such as the inability to solve the problem of omitted variables. This is even more relevant when only limited data are available for important factors, such as bacterial resistance to antimicrobials. A further limitation is represented by the need to impose full regional homogeneity in the parameters of the random process that describes the use of antibiotics. To overcome these problems, we analysed socioeconomic determinants of antibiotic consumption by means of panel data from a new country (Italy).

The consumption of antibiotics cannot be regarded as independently generated within regions because of possible spillover effects. Antibiotics may reduce the risk of infections in neighbouring areas (positive externality) and may reduce the effectiveness of treatment because of bacterial resistance spreading (negative externality). As a consequence, standard estimation procedures employed in many empirical studies can lead to bias and inefficiency in the estimates. Our approach allowed to consider spatial effects across regions. We captured these effects by means of a spatial-lag model and a spatial-error model. 
We found some evidence of spatial autocorrelation in the use of antibiotics across Italian regions. This suggests that regional policies (e.g. public campaigns) aimed at increasing efficiency in antibiotic consumption and controlling bacterial resistance may not be independent and could be influenced by policy makers in neighbouring regions. There will be scope for a strategic and coordinated view of regional policies towards the use of antibiotics. 


\section{References}

Albricht, W., Monnet, D.L. and Harbarth S. (2004) Antibiotic selection pressure and resistance in Streptococcus pneumoniae and Streptococcus pyogenes, Emerging Infectious Diseases, 10, 514-17.

Anselin, L. (1988) Spatial econometrics: Methods and models, Kluwer, Dordrecht, the Netherlands.

Anselin, L. and Bera, A. (1998) Spatial dependence in linear regression models with an introduction to spatial econometrics, in Handbook of Applied Economic Statistics, (Eds) A. Ullah and D.E.A. Giles, Marcel Dekker, New York, pp. 237-89.

Atella, V., Hassell, K, Schafheutle, E., Weiss M.C. and Noyce P.R. (2003) Cost to the patient or cost to the healthcare system? Which one matters the most for GP prescribing decisions? A UK-Italy comparison, CEIS Tor Vergata Research Papers No. 1.

Baltagi, B. (2005) Econometric analysis of panel data, 3rd edn, Wiley, Chichester.

Baye, M.R., Maness, R. and Wiggins, S.N. (1997) Demand systems and the true subindex of the cost of living for pharmaceuticals, Applied Economics, 29, 1179-90.

Bretteville-Jensen, A.L. (2006) Drug demand - initiation, continuation and quitting -, De Economist, 154, 491-516.

Breusch, T. and Pagan, A. (1979) A simple test of heteroskedasticity and random coefficient variation, Econometrica, 47, 1287-94.

Cabrer-Borrás, B. and Serrano-Domingo, G. (2007) Innovation and R\&D spillover effects in Spanish regions: A spatial approach, Research Policy, 36, 1357-71.

Cameron, A. and Trivedi, P. (2005) Microeconometrics. Methods and Applications, Cambridge, Cambridge University Press.

Cliff, A. and Ord, J. 1973 Spatial Autocorrelation, London, Pion.

Cliff, A.D. and Ord, J.K. (1981) Spatial Processes: Models and Applications, London, Pion.

Contoyannis, P., Hurley, J., Grootendorst, P., Jeon, S.H. and Tamblyn, R. (2005)

Estimating the price elasticity of expenditure for prescription drugs in the presence of non-linear price schedules: an illustration from Quebec, Canada. Health Economics, 14, 909-23.

Costa-Font, J., Kanavos, P. and Rovira, J. (2007) Determinants of out-of-pocket pharmaceutical expenditure and access to drugs in Catalonia, Applied Economics, 39, 541-551.

Costa-Font, J., Moscone, F. (2008) The impact of decentralization and inter-territorial interactions on Spanish health expenditure, Empirical Economics, 34, 167-184.

Di Matteo, L. (2005) The macro determinants of health expenditure in the United States and Canada: assessing the impact of income, age distribution and time, Health Policy , 71, 23-42.

Driscoll, J., Kraay, A.C. (1998) Consistent covariance matrix estimation with spatially dependent data, Review of Economics and Statistics, 80, 549-560.

Elhorst, J. (2003) Specification and estimation of spatial panel data Models, International Regional Science Review, 26, 244-68. 
Elseviers, M., Ferech, M., Vander Stichele, R.H. and Goossens, H. (2007) Antibiotic use in ambulatory care in Europe (ESAC data 1997-2002): trends, regional differences and seasonal fluctuations, Pharmacoepidemiology and Drug Safety, 16, 115-123.

European Commission. (2010) Antimicrobial Resistance, Eurobarometer 338/Wave 72.5 - TNS Opinion \& Social, Luxembourg.

Ferech, M., Coenen, S., Dvorakova, K., Hendrickx, E., Suetens, C. and Goossens, H. (2006) European Surveillance of Antimicrobial Consumption (ESAC): outpatient penicillin use in Europe, Journal of Antimicrobial Chemotherapy, 58, 408-12.

Filippini, M., Masiero, G. and Moschetti, K. (2006) Socioeconomic determinants of regional differences in outpatient consumption: Evidence from Switzerland, Health Policy, 78, 77-92.

Filippini, M., Masiero, G. and Moschetti, K. (2009a) Small area variations and welfare loss in the use of outpatient antibiotics, Health Economics, Policy and Law, 4, 55-77.

Filippini, M., Masiero, G. and Moschetti, K. (2009b) Regional consumption of antibiotics: a demand system approach, Economic Modelling, 26, 1389-97.

Fingleton, B. (2003) Externalities, economic geography, and spatial econometrics: conceptual and modeling developments, International Regional Science Review, 26, 197-207.

Fiorio, C. and Siciliani, L. (2010) Co-payments and the demand for pharmaceuticals: Evidence from Italy, Economic Modelling, 27, 835-41.

Freemantle, N. and Bloor, K. (1996) Lessons from international experience in controlling pharmaceutical expenditure I: influencing patients, British Medical Journal, 312, 1469-71.

Geary, R. (1954) The contiguity ratio and statistical mapping, The Incorporated Statistician, 5, 115-45.

Goodchild, M.F. (1987) A spatial analytical perspective on geographical information systems, International Journal of Geographical Information Systems, 1, 327-34.

Gujarati, D.N. (1995) Basic Econometrics, 3rd edn, McGraw-Hill, New York.

Habitch, J., Kiivet, R.A., Habicht, T. and Kunst, A.E. (2009) Social inequalities in the use of health care services after 8 years of health care reforms - a comparative study of the Baltic countries, International Journal of Public Health, 54, 1-10.

Huttner, B., Goossens, H., Verheij, T. and Harbarth, S. on behalf of the CHAMP consortium. (2010) Characteristics and outcomes of public campaigns aimed at improving the use of antibiotics in outpatients in high-income countries, Lancet Infectious Diseases, 10, 17-31.

Kern, W.V., de With, K., Nink, K., Steib-Bauert, M. and Schröder, H. (2006) Regional variation in outpatient antibiotic prescribing in Germany, Infection, 34, 26973.

Masiero, G., Filippini, M., Ferech, M. and Goossens, H. (2010) Socioeconomic determinants of outpatient antibiotic use in Europe, International Journal of Public Health, 55, 469-78.

Matuz, M., Benko, R., Doro, P., Haidu, E., Nagy, G., Nagy, E., Monnet, D.L. and Soos, G. (2005) Regional variations in community consumption of antibiotics in 
Hungary, 1996-2003, British Journal of Clinical Pharmacology, 61, 96-100.

Mera, R.M., Miller, L.A. and White A. (2006) Antibacterial use and Streptococcus pneumoniae penicillin resistance: a temporal relationship model, Microbial Drug Resistance, 12, 158-63.

Monnet, D.L., Mölstad, S. and Cars, O. (2004) Defined daily doses of antimicrobials reflect antimicrobial prescriptions in ambulatory care, Journal of Antimicrobial Chemotherapy, 53,1109-11.

Monroe, S. and Polk, R. (2000) Antimicrobial use and bacterial resistance, Current Opinion in Microbiology, 3, 496-501.

Moran, P. (1948) The interpretation of statistical maps, Journal of the Royal Statistical Society Series B, 10, 243-51.

Moscone, F. and Knapp, M. (2005) Exploring the spatial pattern of mental health Expenditure, Journal of Mental Health Policy and Economics, 8, 205-17.

Nitzan, O., Low, M., Lavi, I., Hammerman, A., Klang, S. and Raz, R. (2010) Variability in outpatient antimicrobial consumption in Israel, Infection, 38, 12-18.

Pisati, M. (2001) Tools for spatial data analysis, Stata Technical Bulletin stb-60.

Revelli, F. (2001) Spatial patterns in local taxation: tax mimicking or error mimicking?, Applied Economics, 33, 1101-07.

Rudholm, N. (2003) Competition and substitutability in the Swedish pharmaceuticals market, Applied Economics, 35, 1609-17. 


\section{QUADERNI DELLA FACOLTÀ}

1998:

P. Balestra, Efficient (and parsimonious) estimation of structural dynamic error component models

1999:

M. Filippini, Cost and scale efficiency in the nursing home sector : evidence from Switzerland

L. Bernardi, I sistemi tributari di oggi : da dove vengono e dove vanno

L.L. Pasinetti, Economic theory and technical progress

G. Barone-Adesi, K. Giannopoulos, L. Vosper, VaR without correlations for portfolios of derivative securities

G. Barone-Adesi, Y. Kim, Incomplete information and the closed-end fund discount

G. Barone-Adesi, W. Allegretto, E. Dinenis, G. Sorwar, Valuation of derivatives based on CKLS interest rate models

M. Filippini, R. Maggi, J. Mägerle, Skalenerträge und optimale Betriebsgrösse bei den schweizerische Privatbahnen

E. Ronchetti, F. Trojani, Robust inference with GMM estimators

G.P. Torricelli, I cambiamenti strutturali dello sviluppo urbano e regionale in Svizzera e

nel Ticino sulla base dei dati dei censimenti federali delle aziende 1985, 1991 e 1995

2000:

E. Barone, G. Barone-Adesi, R. Masera, Requisiti patrimoniali, adeguatezza del capitale e gestione del rischio

G. Barone-Adesi, Does volatility pay?

G. Barone-Adesi, Y. Kim, Incomplete information and the closed-end fund discount

$\mathrm{R}$. Ineichen, Dadi, astragali e gli inizi del calcolo delle probabilità

W. Allegretto, G. Barone-Adesi, E. Dinenis, Y. Lin, G. Sorwar, A new approach to check the free boundary of single factor interest rate put option

G.D.Marangoni, The Leontief Model and Economic Theory

B. Antonioli, R, Fazioli, M. Filippini, // servizio di igiene urbana italiano tra concorrenza e monopolio

L. Crivelli, M. Filippini, D. Lunati. Dimensione ottima degli ospedali in uno Stato federale

L. Buchli, M. Filippini, Estimating the benefits of low flow alleviation in rivers: the case of the Ticino River

L. Bernardi, Fiscalità pubblica centralizzata e federale: aspetti generali e il caso italiano attuale

M. Alderighi, R. Maggi, Adoption and use of new information technology

F. Rossera, The use of log-linear models in transport economics: the problem of

commuters' choice of mode

2001:

M. Filippini, P. Prioni, The influence of ownership on the cost of bus service provision in

Switzerland. An empirical illustration

B. Antonioli, M. Filippini, Optimal size in the waste collection sector

B. Schmitt, La double charge du service de la dette extérieure

L. Crivelli, M. Filippini, D. Lunati, Regulation, ownership and efficiency in the Swiss

nursing home industry

S. Banfi, L. Buchli, M. Filippini, Il valore ricreativo del fiume Ticino per i pescatori

L. Crivelli, M. Filippini, D. Lunati, Effizienz der Pflegeheime in der Schweiz 
2002:

B. Antonioli, M. Filippini, The use of a variable cost function in the regulation of the Italian water industry

B. Antonioli, S. Banfi, M. Filippini, La deregolamentazione del mercato elettrico svizzero e implicazioni a breve termine per l'industria idroelettrica

M. Filippini, J. Wild, M. Kuenzle, Using stochastic frontier analysis for the access price regulation of electricity networks

G. Cassese, On the structure of finitely additive martingales

2003:

M. Filippini, M. Kuenzle, Analisi dell'efficienza di costo delle compagnie di bus italiane e svizzere

C. Cambini, M. Filippini, Competitive tendering and optimal size in the regional bus transportation industry

L. Crivelli, M. Filippini, Federalismo e sistema sanitario svizzero

L. Crivelli, M. Filippini, I. Mosca, Federalismo e spesa sanitaria regionale : analisi empirica per i Cantoni svizzeri

M. Farsi, M. Filippini, Regulation and measuring cost efficiency with panel data models : application to electricity distribution utilities

M. Farsi, M. Filippini, An empirical analysis of cost efficiency in non-profit and public nursing homes

F. Rossera, La distribuzione dei redditi e la loro imposizione fiscale : analisi dei dati fiscali svizzeri

L. Crivelli, G. Domenighetti, M. Filippini, Federalism versus social citizenship :

investigating the preference for equity in health care

M. Farsi, Changes in hospital quality after conversion in ownership status

G. Cozzi, O. Tarola, Mergers, innovations, and inequality

M. Farsi, M. Filippini, M. Kuenzle, Unobserved heterogeneity in stochastic cost frontier models : a comparative analysis

2004:

G. Cassese, An extension of conditional expectation to finitely additive measures

$\mathrm{S}$. Demichelis, O. Tarola, The plant size problem and monopoly pricing

F. Rossera, Struttura dei salari 2000 : valutazioni in base all'inchiesta dell'Ufficio federale di statistica in Ticino

M. Filippini, M. Zola, Economies of scale and cost efficiency in the postal services : empirical evidence from Switzerland

F. Degeorge, F. Derrien, K.L. Womack, Quid pro quo in IPOs : why book-building is dominating auctions

M. Farsi, M. Filippini, W. Greene, Efficiency measurement in network industries : application to the Swiss railway companies

L. Crivelli, M. Filippini, I. Mosca, Federalism and regional health care expenditures : an empirical analysis for the Swiss cantons

S. Alberton, O. Gonzalez, Monitoring a trans-border labour market in view of liberalization : the case of Ticino

M. Filippini, G. Masiero, K. Moschetti, Regional differences in outpatient antibiotic consumption in Switzerland

A.S. Bergantino, S. Bolis, An adaptive conjoint analysis of freight service alternatives :

evaluating the maritime option

2005:

M. Farsi, M. Filippini, An analysis of efficiency and productivity in Swiss hospitals

M. Filippini, G. Masiero, K. Moschetti, Socioeconomic determinants of regional

differences in outpatient antibiotic consumption : evidence from Switzerland 
2006:

M. Farsi, L. Gitto, A statistical analysis of pain relief surgical operations

M. Farsi, G. Ridder, Estimating the out-of-hospital mortality rate using patient discharge data

S. Banfi, M. Farsi, M. Filippini, An empirical analysis of child care demand in Switzerland

L. Crivelli, M. Filippini, Regional public health care spending in Switzerland : an empirical analysis

M. Filippini, B. Lepori, Cost structure, economies of capacity utilization and scope in Swiss higher education institutions

M. Farsi, M. Filippini, Effects of ownership, subsidization and teaching activities on hospital costs in Switzerland

M. Filippini, G. Masiero, K. Moschetti, Small area variations and welfare loss in the use of antibiotics in the community

A. Tchipev, Intermediate products, specialization and the dynamics of wage inequality in the US

A. Tchipev, Technological change and outsourcing : competing or complementary explanations for the rising demand for skills during the 1980s?

2007:

M. Filippini, G. Masiero, K. Moschetti, Characteristics of demand for antibiotics in primary care : an almost ideal demand system approach

G. Masiero, M. Filippini, M. Ferech, H. Goossens, Determinants of outpatient antibiotic consumption in Europe : bacterial resistance and drug prescribers

R. Levaggi, F. Menoncin, Fiscal federalism, patient mobility and the soft budget constraint : a theoretical approach

M. Farsi, The temporal variation of cost-efficiency in Switzerland's hospitals : an application of mixed models

2008

M. Farsi, M. Filippini, D. Lunati, Economies of scale and efficiency measurement in Switzerland's nursing homes

A. Vaona, Inflation persistence, structural breaks and omitted variables : a critical view

A. Vaona, The sensitivity of non parametric misspecification tests to disturbance autocorrelation

A. Vaona, STATA tip : a quick trick to perform a Roy-Zellner test for poolability in STATA

A. Vaona, R. Patuelli, New empirical evidence on local financial development and growth

C. Grimpe, R. Patuelli, Knowledge production in nanomaterials : an application of spatial filtering to regional system of innovation

A. Vaona, G. Ascari, Regional inflation persistence : evidence from Italy

M. Filippini, G. Masiero, K. Moschetti, Dispensing practices and antibiotic use

T. Crossley, M. Jametti, Pension benefit insurance and pension plan portfolio choice

R. Patuelli, A. Vaona, C. Grimpe, Poolability and aggregation problems of regional innovation data : an application to nanomaterial patenting

J.H.L. Oud, H. Folmer, R. Patuelli, P. Nijkamp, A spatial-dependence continuous-time model for regional unemployment in Germany

2009:

J.G. Brida, S. Lionetti, W.A. Risso, Long run economic growth and tourism : inferring from Uruguay

R. Patuelli, D.A. Griffith, M. Tiefelsdorf, P. Nijkamp, Spatial filtering and eigenvector stability : space-time models for German unemployment data

R. Patuelli, A. Reggiani, P. Nijkamp, N. Schanne, Neural networks for cross-sectional employment forecasts : a comparison of model specifications for Germany

A. Cullmann, M. Farsi, M. Filippini, Unobserved heterogeneity and International

benchmarking in public transport

M. Jametti, T. von Ungern-Sternberg, Hurricane insurance in Florida

S. Banfi, M. Filippini, Resource rent taxation and benchmarking : a new perspective for the Swiss hydropower sector 
S. Lionetti, R. Patuelli, Trading cultural goods in the era of digital piracy

M. Filippini, G. Masiero, K. Moschetti, Physician dispensing and antibiotic prescriptions

2010:

Quaderno n. 10-01

R. Patuelli, N. Schanne, D.A. Griffith, P. Nijkamp, Persistent disparities in regional unemployment : application of a spatial filtering approach to local labour markets in Germany

Quaderno n. 10-02

K. Deb, M. Filippini, Public bus transport demand elasticities in India

Quaderno n. 10-03

L. Masiero, R. Maggi, Estimation of indirect cost and evaluation of protective measures

for infrastructure vulnerability : a case study on the transalpine transport corridor

Quaderno n. 10-04

L. Masiero, D.A. Hensher, Analyzing loss aversion and diminishing sensitivity in a freight transport stated choice experiment

Quaderno n. 10-05

L. Masiero, D.A. Hensher, Shift of reference point and implications on behavioral reaction

to gains and losses

Quaderno n. 10-06

J.M. Rose, L. Masiero, A comparison of prospect theory in WTP and preference space Quaderno n. 10-07

M. Filippini, M. Koller, U. Trinkner, Do opening hours and unobserved heterogeneity affect economies of scale and scope in postal outlets?

Quaderno n. 10-08

G. Guerra, R. Patuelli, R. Maggi, Ethnic concentration, cultural identity and immigrant self-employment in Switzerland

Quaderno n. 10-09

S. Lionetti, Tourism productivity : incentives and obstacles to fostering growth

Quaderno n. 10-10

G. Guerra, R. Patuelli, The influence of role models on immigrant self-employment : a spatial analysis for Switzerland

Quaderno n. 10-11

M. Filippini, L. Gonzalez, G. Masiero, Estimating dynamic consumption of antibiotics using panel data : the shadow effect of bacterial resistance

2011:

Quaderno n. 11-01

L. Masiero, J.L. Nicolau, Price sensitivity to tourism activities : looking for determinant factors

Quaderno n. 11-02

L. Masiero, J.L. Nicolau, Finding similar price preferences on tourism activities

Quaderno n. 11-03

L. Masiero, R. Maggi, Accounting for WTP/WTA discrepancy in discrete choice models :

discussion of policy implications based on two freight transport stated choice experiments Quaderno n. 11-04

L. Masiero, J.M. Rose, The role of the reference alternative in the specification of asymmetric discrete choice models 


\section{Quaderno n. 11-05}

D. Engel, T. Mitze, R. Patuelli, J. Reinkowski, Does the support of innovative clusters sustainably foster $R \& D$ activity? Evidence from the German BioRegio and BioProfile contests

Quaderno n. 11-06

L. González, G. Masiero, Disentangling spillover effects of antibiotic consumption : a spatial panel approach 